\title{
Removal of airborne hexavalent chromium mist using chitosan gel beads as a new control approach
}

\author{
${ }^{1}$ A. Tirgar, ${ }^{1 *}$ F. Golbabaei, ${ }^{2}$ J. Hamedi, ${ }^{1}$ K. Nourijelyani, ${ }^{1}$ S. J. Shahtaheri and ${ }^{3}$ S. R. Moosavi \\ ${ }^{1}$ Department of Occupational Health Engineering, School of Public Health and Institute of Health Research Center, \\ Tehran University of Medical Science, Tehran, Iran \\ ${ }^{2}$ School of Biology, College of Science, University of Tehran, Tehran, Iran \\ ${ }^{3}$ Department of Chemistry, Sharif University of Technology, Tehran, Iran
}

Received 8 May 2006; revised 8 June 2006; accepted 17 June 2006; available online 25 June 2006

\begin{abstract}
Airborne hexavalent chromium is a known human respiratory carcinogen and allergen. Many workers are exposed to hexavalent chromium in various processes which chromium electroplating plants are the most common. In this study, the feasibility of a new control approach to remove this pollutant using chitosan beads as a biosorbent was investigated. Hexavalent chromium sorption was studied relative to $\mathrm{pH}$, pollution concentration, sorbent concentration, temperature, and air velocity using one factor at a time approach and Taguchi experimental design. Polluted air with different chromium mist concentrations $\left(10-5000 \mu \mathrm{g} / \mathrm{m}^{3}\right)$ was contacted to chitosan beads $(3.3-20 \mathrm{~g} / \mathrm{L})$, floating in distilled water with adjusted $\mathrm{pH}$ (3-7), using an impinger at different temperatures (20 and $35{ }^{\circ} \mathrm{C}$ ), and various velocities (1.12 and $2.24 \mathrm{~m} / \mathrm{s}$ ). The ANOVA test result showed that, there were statistical significant differences between factor levels except optimized $\mathrm{pH}$ levels. The higher ions removal efficiencies were achieved at lower levels of air velocities, pollution concentrations, and higher levels of solution $\mathrm{pH}$ values, temperatures, and sorbent concentrations.
\end{abstract}

Key words: Chitosan, biosorbent, hexavalent chromium mist, control, removal

\section{INTRODUCTION}

Hexavalent chromium, $\mathrm{Cr}(\mathrm{VI})$, is a human respiratory carcinogen and allergen that are limited by the law due to its toxic properties. It is emitted into the air, water, and soil by a number of industrial and military operations including metal plating, paining, cooling-tower and chromate ore processing; combustion sources such as automobiles and incinerators (Sheehan et al., 1992; Mancuso, 1997 and Ashely et al., 2003). Cr (VI) in sublethal concentration can damage the gills of fish. In animals, chromium can cause respiratory problems, birth defects, infertility and tumor formation. Thus, control of $\mathrm{Cr}$ (VI) emission is an important issue in both industrial hygiene and environmental protection. The use of dead biomass and biomass derivatives (biosorbent materials) to remove heavy metals from aqueous solutions has been widely studied in recent years (Araujo and Teixeira, 1997). It has been recognized as a potential method to reduce metals contamination in surface water, ground water and in industrial effluents. These methods are less

*Corresponding author, Email: gol128@sphtums.com

Tel.: +9821-6646 5404 Fax: +9821-6646 2267 expensive than the traditional physicochemical processes. They do not need nutrients and are resistant to the physical-chemical properties of heavy metal solutions. No reports were seen about airborne heavy metals removal using a biomass derivative at the time of this study. Thus, this paper deals in particular with the study of airborne $\mathrm{Cr}$ (VI) removal by chitosan gel beads. Preliminary results obtained from our recent study are now under more investigation. Chitosan results from the deacetylation of chitin are the most abundant biopolymer in nature after cellulose (Guibal et al., 1999 and Guibal et al., 2001). It is a polysaccharide with high content of amino groups that are able to sorb metals through several mechanisms including chemical interactions, such as chelation, electrostatic interactions, like ion exchange, or the formation of ion pairs. The kind of interaction depends on the metal, its chemistry, and the $\mathrm{pH}$ of the solution (Dzul Erosa et al., 2001). Several studies have been performed on its sorption capacity, using native chitin, chitosan or more sophisticated forms resulting from a grafting of specific functional groups (Guibal et al., 1999 and Guibal et al., 2000). The aim of 
this work was to investigate the feasibility of a new approach to remove airborne $\mathrm{Cr}$ (VI)from electroplating bath emission using chitosan beads. This study was focused hexavalent chromium removal efficiency of chitosan at different conditions of effective parameters including: $\mathrm{Cr}$ (VI) concentration, biosorbent concentration, $\mathrm{pH}$, temperature, and impaction velocity of polluted air with sorbent.

\section{MATERIALS AND METHODS}

This research project has been carried out in occupational health laboratory, School of public health, Tehran University of medical sciences from October 2005 to February 2006.

\section{Beads preparation and characterization}

Chitosan flakes from Crab Shell with at least 85\% deacetylation [Sigma-Aldrich Co.] (2\%, w/w) was dissolved in an acetic acid solution (4\%, w/w), and introduced dropwise into a coagulating bath (sodium hydroxide $2.5 \mathrm{M}$ ). In the alkaline solution, the beads kept their initial spherical forms and formed chitosan beads (Fig. 1) (Guibal et al., 1998 and Guibal et al., 1999). The beads were stirred in $\mathrm{NaOH}$ solution on the orbital shaker at $250 \mathrm{rpm}$ for $24 \mathrm{~h}$. Then, they were washed three times with distilled water and kept in a $2.5 \mathrm{M} \mathrm{NaOH}$ solution at $4{ }^{\circ} \mathrm{C}$. Immediately before using, the chitosan beads were washed again three times with distilled water and the excess water was absorbed on paper filter. The mean diameter of beads was determined in 10 groups of 50 chitosan beads using a micrometer $(3.06 \pm 0.01 \mathrm{~mm})$. The mean weight of the beads was determined using 10 samples of 20 beads $(13.64 \pm 1.05 \mathrm{mg})$. The solid content of the chitosan beads were determined by weighting before and after drying at $60{ }^{\circ} \mathrm{C}$ overnight (for $24 \mathrm{~h}$ ) $[6.11 \pm 0.64 \%(\mathrm{w} / \mathrm{w})]$.

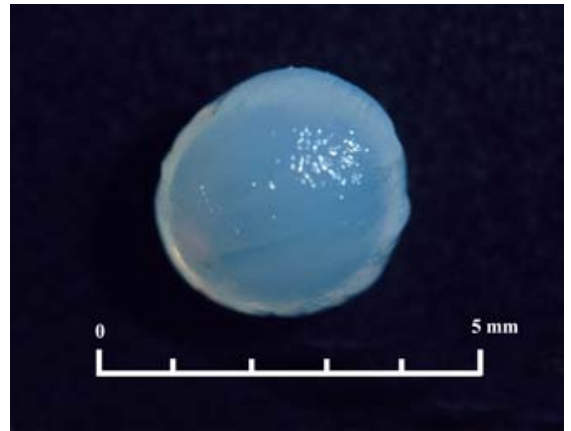

Fig. 1: Size and physical shape of chitosan bead

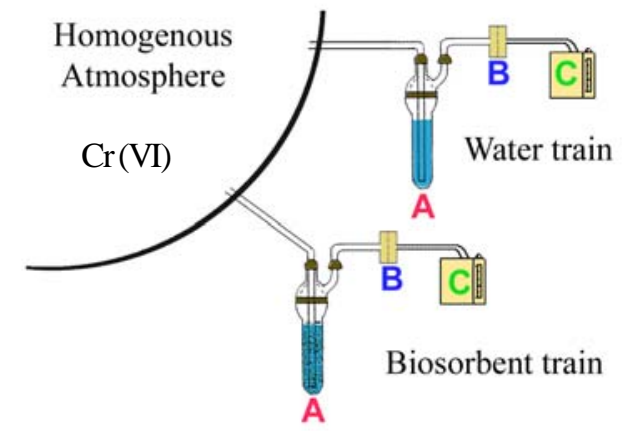

Fig. 2: Set up of the sampling trains A: Air sampler B: Polystyrene cassette C: Personal sampling pump

\section{Metal binding capacity}

Optimum removal conditions for Cr (VI) were investigated using a special electroplating bath as a $\mathrm{Cr}$ (VI) generator (Tirgar et al., 2006), as well as simultaneous application of two sampling trains shown in Fig. 2.

\section{Sampling train with biosorbent}

Sampling train with biosorbent (biosorbent train) consisted of following compartments: A) a standard air sampler named midget impinger (SKC, Inc.) containing chitosan beads and $15 \mathrm{~mL}$ water with adjusted $\mathrm{pH}$ in thermostatically controlled water bath (Part A in Fig. 2). B) a 37-mm polystyrene filter cassette containing a $5.0 \mu \mathrm{m}$ pore size polyvinyl chloride (PVC) membrane filter (MSA, USA). C) a personal sampling pump (Model 224-PCXR3; SKC, Inc.) calibrated for air flow rate of 1 or $2.0 \pm 0.1 \mathrm{l} / \mathrm{min}$.

\section{Sampling train without biosorbent}

Sampling train without biosorbent (water train) completely was the same as biosorbent train except midget impinger contained $15 \mathrm{~mL}$ distilled water with a relevant adjusted $\mathrm{pH}$. It should be noted that, sampling duration for all samples were the same i.e. $60 \mathrm{~min}$. The difference between chromium concentration in biosorbent train and water train was considered as chitosan-bounded chromium.

The percent of chromium ions adsorbed under experimental conditions was evaluated as $\left[\left(\mathrm{C}_{\mathrm{W}}-\mathrm{C}_{\mathrm{B}}\right) / \mathrm{C}_{\mathrm{W}}\right]$ $\times 100 . C_{W}$ and $C_{B}$ are the concentration of the metal ions in the water and biosorbent solution $(\mathrm{mg} / \mathrm{L})$ after sampling, respectively. 
Optimization using one factor at a time approach (primary optimization)

In this stage, the effects of solution $\mathrm{pH}, \mathrm{Cr}$ (VI) concentration and sorbent concentration were studied. The effect of $\mathrm{pH}$ on the biosorption rate of $\mathrm{Cr}$ (VI) ions by the chitosan beads were investigated in 2 steps. Suitable pH was first determined among 5, 7, and 9, then according to the result of the highest removal efficiency in acidic condition, further experiments continued at the range of 3-6. The $\mathrm{pH}$ was adjusted with $0.1 \mathrm{M} \mathrm{HNO}_{3}$ or $\mathrm{NaOH}$ at the beginning of the experiments. The effect of $\mathrm{Cr}$ (VI) concentration was studied at three different levels at optimized solution $\mathrm{pH}$ including low, medium, and high $\left(<50,50-500\right.$, and 500-5000 $\left.\mu \mathrm{g} / \mathrm{m}^{3}\right)$. In addition, the effect of biosorbent concentration was determined after the $\mathrm{pH}$ and $\mathrm{Cr}$ (VI) concentration optimization at three different levels (3.3, 10, and $20 \mathrm{mg} / \mathrm{mL})$.

Optimization using Taguchi method (secondary optimization)

In second stage, five factors at two levels were studied by standard L16 $\left(2^{5}\right)$ Taguchi orthogonal array (Table 1). As Table 1 shows, studied factor levels of air velocity, sorbent concentration, $\mathrm{pH}$, temperature and $\mathrm{Cr}$ (VI) concentration are as follows: 1.12 and $2.24 \mathrm{~m} / \mathrm{s}$, 10 and $20 \mathrm{~g} / \mathrm{L}, 5$ and 6 values, 20 and $35^{\circ} \mathrm{C},<50$ and 50$500 \mu \mathrm{g} / \mathrm{m}^{3}$, respectively. The analyses of data were done by Qualitek-4 statistical software.

\section{Analytical method}

Determination of metal concentration in all experiments was performed using a Shimadzu AA 680 Atomic Absorption Spectrometer. The instrument response was periodically checked with known standards. A calibration curve obtained with a correlation coefficient of at least 0.98 . The samples were read three times and the mean value, as well as the relative standard deviation, was calculated. The samples were diluted as required to remain within the calibration linear range. The wavelength of 357.7 $\mathrm{nm}$ was used for chromium ions studied (Cornelis, 1994).

\section{RESULTS}

\section{Primary optimization}

The results obtained on the effects of $\mathrm{pH}, \mathrm{Cr}$ (VI) concentration, and sorbent concentration using one factor at a time experimental design have been summarized in Fig. 3. As the plots show, sorption efficiency has been considerably influenced by the $\mathrm{pH}$ and sorbent concentration. Sorption efficiency increased first with increasing the $\mathrm{pH}$ and then reached a maximum at about 5-6. However, it decreased with a further increase. In an ascertain manner, increase in sorbent concentration induced an increase on removal efficiency.

Table 1: removal of $\mathrm{Cr}(\mathrm{VI})$ by chitosan at different factor levels under L16 Taguchi orthogonal array

\begin{tabular}{cccccl}
\hline Run & $\begin{array}{c}\text { Air } \\
\text { velocity } \\
(\mathrm{m} / \mathrm{s})\end{array}$ & $\begin{array}{c}\text { Sorbent } \\
\text { con. }(\mathrm{g} / \mathrm{L})\end{array}$ & $\mathrm{pH}$ & $\begin{array}{c}\text { Temperature } \\
\left({ }^{\circ} \mathrm{C}\right)\end{array}$ & $\begin{array}{c}\mathrm{Cr}(\mathrm{VI}) \mathrm{con} . \\
\left(\mu \mathrm{g} / \mathrm{m}^{3}\right)\end{array}$ \\
\hline 1 & 1.12 & 10 & 5 & 20 & $<50$ \\
2 & 1.12 & 10 & 5 & 35 & $50-500$ \\
3 & 1.12 & 10 & 6 & 20 & $50-500$ \\
4 & 1.12 & 10 & 6 & 35 & $<50$ \\
& & & & & \\
5 & 1.12 & 20 & 5 & 20 & $50-500$ \\
6 & 1.12 & 20 & 5 & 35 & $<50$ \\
7 & 1.12 & 20 & 6 & 20 & $<50$ \\
8 & 1.12 & 20 & 6 & 35 & $50-500$ \\
& & & & & \\
9 & 2.24 & 10 & 5 & 20 & $50-500$ \\
10 & 2.24 & 10 & 5 & 35 & $<50$ \\
11 & 2.24 & 10 & 6 & 20 & $<50$ \\
12 & 2.24 & 10 & 6 & 35 & $50-500$ \\
& & & & & \\
13 & 2.24 & 20 & 5 & 20 & $<50$ \\
14 & 2.24 & 20 & 5 & 35 & $50-500$ \\
15 & 2.24 & 20 & 6 & 20 & $50-500$ \\
16 & 2.24 & 20 & 6 & 35 & $<50$ \\
\hline
\end{tabular}


Table 2: Descriptive data for 64 samples collected under Taguchi experimental design and its statistical test result

\begin{tabular}{lcccc}
\hline \multicolumn{1}{c}{ Factor } & Levels & Cr (VI) removal (\%) & SD & P-value \\
\hline \multirow{2}{*}{$\mathrm{pH}$} & 1 & 34.72 & 10.49 & 0.102 \\
Temperature & 2 & 37.34 & 8.71 & \\
$\left({ }^{\circ} \mathrm{C}\right)$ & 1 & 33.89 & 9.71 & 0.009 \\
Sorbent con. $(\mathrm{g} / \mathrm{L})$ & 2 & 38.17 & 9.26 & \multirow{2}{*}{0.014} \\
$\mathrm{Cr}(\mathrm{VI})$ con. & 1 & 34.01 & 8.58 & \multirow{2}{*}{0.0001} \\
$\left(\mu \mathrm{g} / \mathrm{m}^{3}\right)$ & 2 & 38.04 & 10.36 & \multirow{2}{*}{0.0008} \\
Air velocity $(\mathrm{m} / \mathrm{s})$ & 1 & 40.38 & 8.85 & 8.91 \\
\hline
\end{tabular}

According to the primary optimization test results, the highest $\mathrm{Cr}$ (VI) removal obtained at $\mathrm{pH} 6$, low $\mathrm{Cr}$ (VI) concentration $\left(<50 \mu \mathrm{g} / \mathrm{m}^{3}\right)$, and high sorbent concentration $(20 \mathrm{mg} / \mathrm{mL})$. Other conditions including $\mathrm{pH}$ 5, medium Cr (VI) (50-500 $\left.\mu \mathrm{g} / \mathrm{m}^{3}\right)$ and sorbent concentrations $(10 \mathrm{mg} / \mathrm{mL})$ were in the second preference of removal efficiency which considered to be used for secondary optimization. The results presented below represent the mean values of at least three replications.

\section{Secondary optimization}

Table 2 shows the descriptive data and the ANOVA test results for 64 (16 runs with 4 replications) collected samples under Taguchi experimental design. As indicated, except $\mathrm{pH}$ due to prior optimization, there were significant differences between two levels of all main factors on $\mathrm{Cr}$ (VI) removal under the optimized levels $(P<0.05)$. Fig. 4 demonstrated Cr (VI) removal efficiency trend at the each of factor levels.

\section{DISCUSSION AND CONCLUSION Influence of $\mathrm{pH}$}

The solution $\mathrm{pH}$ has been identified as the most important variable governing metal adsorption in biosorbents. The medium $\mathrm{pH}$ affects on solubility of metal ions and the ionization state of functional groups. The sorption in chitosan beads is basically electrostatic attraction type (Juang and Ju, 1997), the low sorption efficiency at $\mathrm{pH}<3$ is probably due to a weak interaction between the ammonium groups of chitosan beads and chromium ions. An increase in sorption efficiency by increasing $\mathrm{pH}$ is a result of the higher binding of $\mathrm{Cr}_{2} \mathrm{O}_{7}^{2-}$ with ammonium groups. $\mathrm{Cr}(\mathrm{VI})$ forms dichromate anion at $\mathrm{pH} 4$. This leads to the interaction between $\mathrm{NH}^{3+}$ functional groups in chitosan and $\mathrm{Cr}_{2} \mathrm{O}_{7}^{2-}$ (Fig. 5) (Boddu and Smith, 2002). In addition, a drop in sorption efficiency at $\mathrm{pH}>6$ is likely due to competition reaction of $\mathrm{OH}^{-}$ions and the ammonium groups with chromium ions.

The ANOVA test result shows no significant difference between two optimized levels $(P>0.05)$, however, as the plots show, $\mathrm{Cr}$ (VI) removal efficiency is considerably influenced by the $\mathrm{pH}$. It seems that, a variation of less than 1 unit in the $\mathrm{pH}$ at optimized levels do not cause significant effect on the removal efficiency. According to Tobin et al. a variation of less than 0.5 units in the $\mathrm{pH}$ dose not affect the removal efficiency values (Marroun et al., 1998). Schmuhl et al. (2001) studied the effect of the $\mathrm{pH}$ (varied between $\mathrm{pH}$ 2 and 11) on $\mathrm{Cr}$ (VI) sorption using chitosan beads. However, this study has been done on Cr (VI) ion removal from water and there is not similar report in case of polluted air. They reported that, the maximum adsorption of $\mathrm{Cr}$ (VI) occurred at $\mathrm{pH} 5$ and decreased at lower and higher $\mathrm{pH}$. Above $\mathrm{pH} 7$ a plateau is observed (Schmuhl et al., 2001). Juang and Ju also in a same study regarding the effect of $\mathrm{pH}$ on $\mathrm{Cu}$ (II) ions adsorption on chitosan beads (ranged 3-9) reported that, removal efficiency increased first with increasing the $\mathrm{pH}$ and then reached a maximum at about $\mathrm{pH} 5-6$, but, it decreased sharply with a further increase in equilibrium pH (Juang and Ju, 1997). The same trend for $\mathrm{pH}$ was observed in the sorption of vanadium ions on chitosan (Jansson-Chrrier et al., 1996). The pH experiments for heavy metal ion binding by chitosan beads demonstrated that heavy metal ion uptake was minimum at low $\mathrm{pH}$ value. So, it is concluded that the desertion of $\mathrm{Cr}$ (VI) from biopolymer could be performed by reducing the $\mathrm{pH}$.

\section{Influence of sorbent concentration}

As Fig. 3 shows, increasing chitosan concentration between 3.3 to $20 \mathrm{mg} / \mathrm{mL}$ enhanced $\mathrm{Cr}$ (VI) removal 

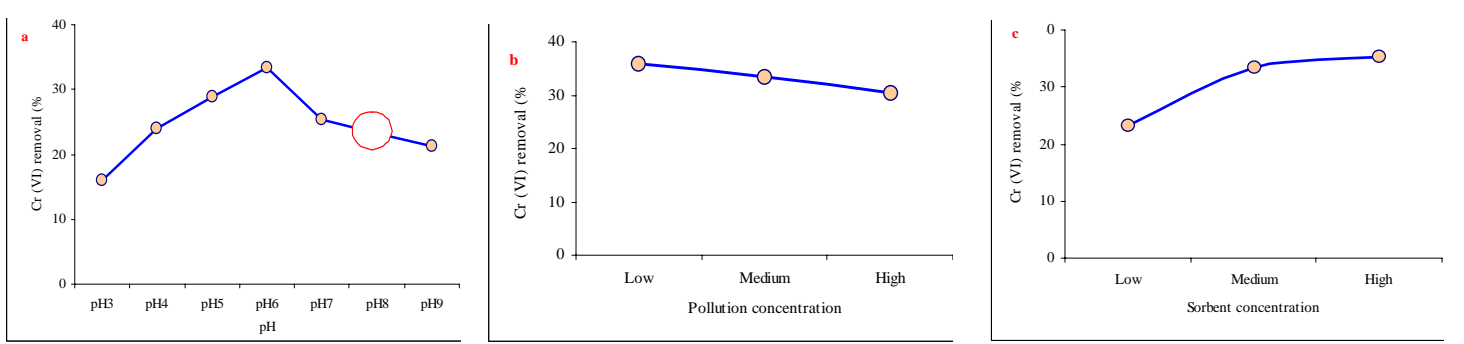

Fig. 3: Screening test results as a function of a) $\mathrm{pH}$, b) pollution, and c) sorbent concentrations at $20^{\circ} \mathrm{C}$ and air velocity of $2.24 \mathrm{~m} / \mathrm{s}$. Result presented by hollow circle $(\mathrm{O})$ in a graph was not performed

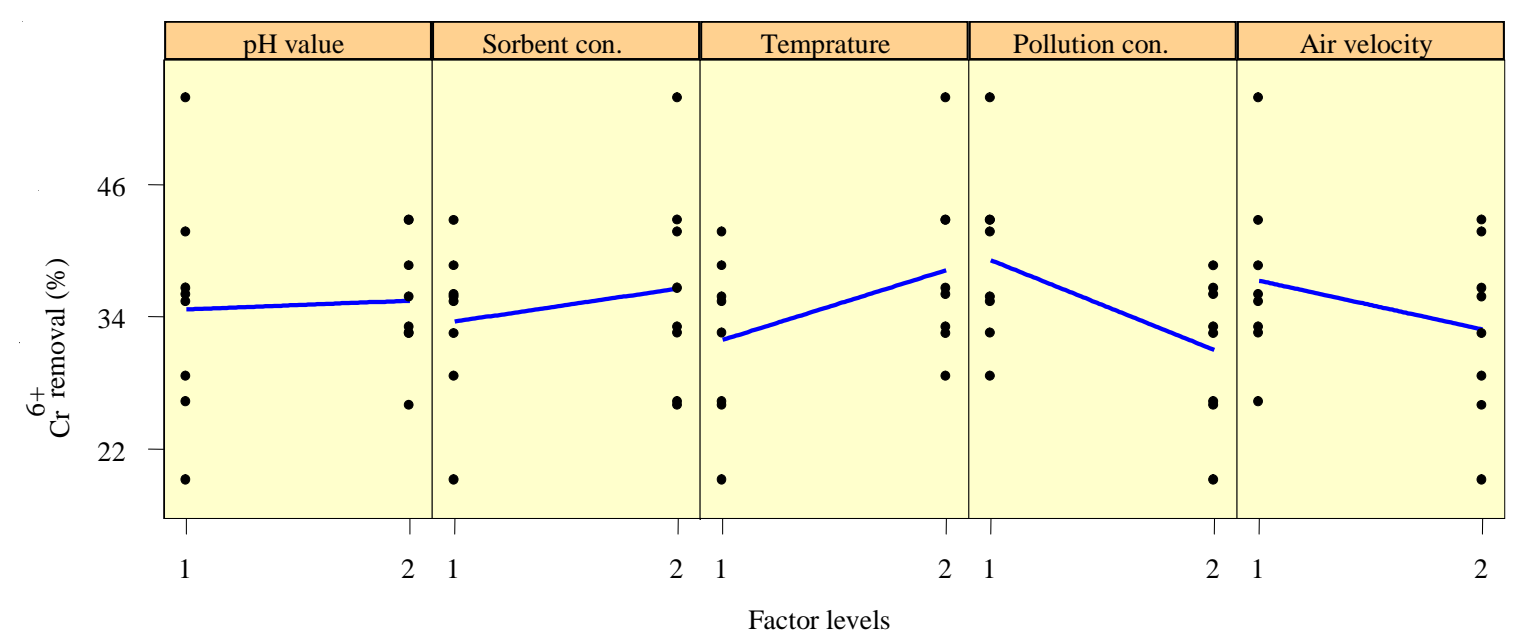

Fig. 4: Effect of air velocity, solution $\mathrm{pH}$, sorbent concentration, pollution concentration, and temperature levels on $\mathrm{Cr}$ (VI) removal by chitosan beads
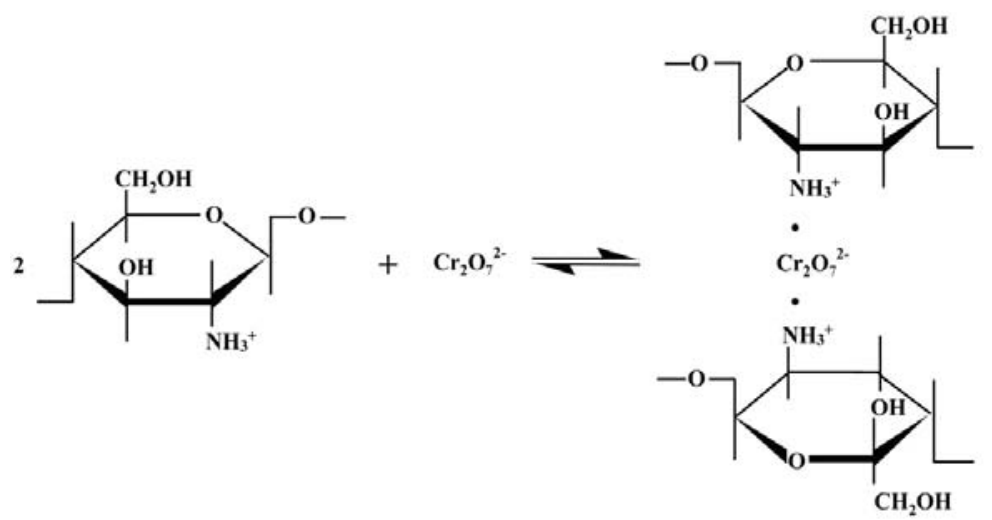

Fig. 5: Interaction between $\mathrm{NH}^{3+}$ functional groups in chitosan and $\mathrm{Cr}_{2} \mathrm{O}_{7}^{2-}$ 
(from 23.13 to $35.19 \%$ ). In addition, the ANOVA test result showed there is a significant difference between the chromium removal in concentrations 10 and $20 \mathrm{mg} /$ $\mathrm{mL}$ (38.08 against $34.01 \%)(P<0.05)$. Our results have revealed that, the $\mathrm{Cr}(\mathrm{VI})$ removal from air using chitosan beads is affected by the sorbent concentration. Similar trend was reported by Chand et al. They observed that higher sorbent (bagasse) concentration gave the greater Cr (VI) removal. However, up to a certain level and beyond more or less constant removal was happened (Chand et al., 1994). Results, in general, have revealed that, the Cr (VI) removal from air was not strongly affected by the sorbent concentration at the range of 10 and $20 \mathrm{mg} / \mathrm{mL}$.

\section{Influence of temperature}

As it shown in Table 2 and Fig. 4, maximum binding capacity values were mostly at $35^{\circ} \mathrm{C}$ and the ANOVA test result shows statistical significant difference between two levels (38.17 \pm 9.26 vs. 33.89 \pm 9.71$)(P<0.05)$. Thus, the biosorption of $\mathrm{Cr}$ (VI) by chitosan beads seems to be temperature dependent in the range of 20 to $35^{\circ} \mathrm{C}$.

Similar to these results, Juang and Ju reported that the higher temperature (in the range of 15 to 45) favore the sorption of metal ions sorption (Cu-EDTA chelate anions) on cross-linked, polyaminated chitosan beads (Juang and Ju, 1997). Dzul Erosa et al. also stated that, temperature hardly influenced equilibrium and kinetic of cadmium sorption on chitosan (between $10-40{ }^{\circ} \mathrm{C}$ ). (Dzul Erosa et al., 2001)

\section{Influence of air pollution concentration}

Table 2 and Fig. 4 illustrated the influence of the airborne $\mathrm{Cr}$ (VI) with different concentration $(<50$ and $50-500 \mu \mathrm{g} / \mathrm{m}^{3}$ ) on sorption behavior of chitosan beads. As shown, an increase in Cr (VI) concentration had significant negative effect on removal efficiency $(P<0.05)$ and induced a decrease about $20 \%$. As depicted in Fig. 3 and 4, higher adsorptions were observed at lower concentration of metal ions. Similar trends have been reported by other researchers (Chand et al., 1994). So, it can be stated that, this process is more applicable for low pollution concentrations.

\section{Influence of air velocity}

Agitation is a classic parameter in sorption phenomena. It influences on the distribution of the solute in the bulk solution. However, it can also act on the formation of the external boundary film (JanssonChrrier et al., 1996). In order to investigate the effect of contact time and agitation rate on Cr (VI) removal, polluted air samples were passed through the sorbent medium with different air velocity. Fig. 4 and Table 2 show that $\mathrm{Cr}$ (VI) uptake is decreased with the increase in air velocity, and there is statistical significant difference between $\mathrm{Cr}$ (VI) uptake at 1.12 and $2.24 \mathrm{~m} / \mathrm{s}$ (33.2 \pm 19.67 against 38.84 \pm 8.91$)(P<0.05)$. So, it can be concluded that, however, agitation facilitate a proper contact between the metal ions in solution and biomass binding sites and thereby, it promotes effective transfer of sorbate ions to the sorbent sites (Ahalya et al., 2002), higher air velocity lead a reduction in the retention time, and the solute has not enough time to diffuse into the whole mass of the sorbent. The slight effect of agitation implies that external mass transfer is not the sole rate limiting phase of sorption. However, Findon et al. reported that, copper and mercury sorption is not dependent on the agitation speed (Guibal et al., 1998). The results demonstrated that, Chitosan is an effective sorbent of Cr (VI) and the sorption is significantly influenced by parameters such as sorbent concentration, temperature, air pollution concentration, and air velocity. In addition, maximum removal of $\mathrm{Cr}$ (VI) by chitosan beads could be obtainable at $\mathrm{pH}$ around 5-6, lower levels of air velocity and Cr (VI) concentration, higher levels of sorbent concentration and temperature. Obviously, higher removal efficiency could be predictable, using suitable forms resulting from some modifications of the polymer. Although proposed airborne $\mathrm{Cr}$ (VI) removal system can work in broad range of working conditions at industrial scales, it is more applicable for low $\mathrm{Cr}$ (VI) concentrations. These concentrations are those, in which, their removal are more difficult or rather expensive using traditional or modern control methods.

\section{ACKNOWLEDGMENTS}

Special thanks are owed to the School of Public Health and Institute of Public Health Research, Tehran University of Medical Sciences, Iran for funding this research (grant No. 2655). The authors also thank Mrs. P. Jamei for her valuable assistance in sample analyses.

\section{REFERENCES}

Ahalya, N., Kanamadi, R. D. and Ramachanda, T. V., (2005). Biosorption of chromium (VI) from aqueous solutions by the husk of Bangal gram (Cicer arientium). J. Biotechnol., 8, 258-264. 
Araujo, M. M. and Teixeira, J. A., (1997). Trivalent chromium sorption on alginate beads. Int. Biodeterior. Biodegrad., 40 (1), 63-74.

Ashley, K., Howe, A. M., Demang, M. and Nygren, O., (2003). Sampling and analysis consideration for the determination of hexavalent chromium in workplace air. J. Environ. Monit., 5, 707-716.

Boddu, V. M. and Smoth, E. D., (2002). A composite chitosan biosorbent for adsorption of heavy metals from wastewaters. <http://www.asc2002.com/manuscripts/E/EPD1standby.pdf >

Chand, S., Agarwal, V. K. and Kumar, P., (1994). Removal of hexavalent chromium from wastewater by adsorption. Indian J. Environ. Health., 36, 151-158.

Cornelis, R., (1994). Chromium in Herber R.F.M Stoeppler M. Trace element analysis in biological. Elsevier science, Nederland, Chapter 16, 343-349.

Dzul Erosa, M. S., Saucedo Medina, T. I., Navaro Mendoza, R., Avila Rodrguez, M. and Guibal, E., (2001). Cadminm sorption on chitosan sorbents: kinetic and equilibrium studies. Hydrometallurgy, 61, 157-167.

Gibb, H. J., Lees, P. S., Pinsky, P. F. and Rooney, B. C., (2000). Lung cancer exposure-response among chromium production workers. Am. J. Ind. Med., 38, 115-126.

Guibal, E., Milot, C. and Tobin, J. M., (1998). Metal-anion sorption by chitosan beads: equilibrium a kinetic studies. Ind. Eng. Chem. Res., 37 (4), 1454-1463.

Guibal, E., Vincent, T. and Navarro Mendoza, R., (2000). Synthesis and characterization of a thiourea derivative of chitosan for platinum recovery. J. Appl. Polym. Sci., 75, 119-134.
Guibal, E. Von Offenberg Sweeney, N. Zikan, M.C. Vincent, T. and Tobin, J. M., (2001). Comparative sorption of platinum and palladium on chitosan derivatives. Int. J. Biologic. Macromol., 28, 401-408.

Jansson-charrier, M., Guibal, E., Roussy, J., Delanghe, B. and Le Cloirec, P., (1996). Vanadium (IV) sorption by chitosan: kinetic and equilibrium. Wat. Res., 30 (2), 467-475.

Juang, R. S. and Ju, C. Y., (1997). Equilibrium sorption of copper (II)-ethylendiaminetetraacetic acid chelates onto cross-linked, polyaminated chitosan beads. Ind. Eng. Chem. Res., 36, 5403-5409.

Mancuso, T. F., (1997). Chromium as an industrial carcinogen. Part I. Am. J. Ind. Med., 31, 129-139.

Merroun, M. L., Ben Omar, M., Gonzalez-Munoz, M. T. and Arias, J. M., (1998). Myxococcus Xanthus biomass as biosorbent for lead. J. Appl. Mmicrobiol., 84, 63-67.

Schmuhl, R., Krieg, H. M. and Keizer, K., (2001). Adsorption of $\mathrm{Cu}$ (II) and $\mathrm{Cr}$ (VI) ions by chitosan: kinetic and equilibrium studies. Water S.A., 27 (1), 1-8. <http://www.wrc.org.za>

Sheehan, P., Ricks, R., Ripple, S. and Paustenbach, D., (1992). Field evaluation of a sampling and analytical method for environmental level of airborne hexavalen chromium. Am. Ind. Hyg. Assoc. J., 53 (1), 57-6.

Tirgar, A., Golbabei, F., Nourijelyani, K., Shahtaheri, S. J., Ganjali, M. R. and Hamedi, J., (2006). Design and performance of chromium mist generator. J. Braz. Chem. Soc., 17 (2), 342-347. 


\section{AUTHOR(S) BIOSKETCHES}

Tirgar, A., MSPH., lecturer in the Department of Social Medicine, Babol Medical Sciences University, and Ph.D. research student in Occupational Health Department at the School of Public Health and Institute of Public Health Research, Tehran University of Medical Sciences, Tehran, Iran.Email:aram@sphtums.com

Golbabaei, F., MSPH., Ph.D., professor in Occupational Health Department at the School of Public Health and Institute of Public Health Research, Tehran University of Medical Sciences., Tehran, Iran. Email:gol128@sphtums.com

Hamedi, J., Ph.D., assistant professor in Microbial Biotechnology Laboratory at the School of Biology, College of Science, University of Tehran. Tehran, Iran. Email: jhamedi@khayam.ut.ac.ir

Nourijelyani, K., MSPH., Ph.D., assistant professor in Epidemiology and Biostatistics Department at the School of Public Health and Institute of Public Health Research, Tehran University of Medical Sciences. Tehran, Iran. Email: nouri4@yahoo.com

Shahtaheri, S. J., MSPH., Ph.D., associate professor in Occupational Health Department at the School of Public Health and Institute of Public Health Research, Tehran University of Medical Sciences, Tehran, Iran. Email: sjtaheri@sphtums.com

Moosavi, S. R., M.Sc., lecturer in Chemistry Department, Sharif University of Technology, Tehran, Iran.Email: mousavi@sharif.edu

This article should be referenced as follows:

Tirgar, A., Golbabaei, F., Hamedi, J., Nourijelyani, K., Shahtaheri, S. J. and Moosavi, S. R., (2006). Removal of airborne hexavalent chromium mist using chitosan gel beads as a new control approach Int. J. Environ. Sci. Tech., 3 (3), 305-312. 